\title{
Solving Logic Problems with Associative Networks in the Course of Knowledge Representation
}

\author{
Martin Zacek \& Vera Ferdianova \\ University of Ostrava, Faculty of Science, Czech Republic
}

\begin{abstract}
This article aims to study of the use Associative (Semantic) networks in the course of Knowledge representation that is taught at the University of Ostrava. In the course was created logic puzzles of type Zebra from simple to more complex levels (Einstein's problems). Associative networks have been used to solve logic puzzles.
\end{abstract}

KEYWORD: Associative networks; semantic networks; graph theory; logic puzzle; zebra; representation knowledge

\section{LOGICAL THINKING}

\subsection{Theoretical perspective}

In a Psychology Dictionary the logical thinking is defined as a developmentally higher form of thinking which is based on correct reasoning according to the laws of formal logic. Foreign Words Dictionary defines formal logic as learning about laws and rules needed for obtaining truthful conclusions while reasoning. Aristotle is considered its founder.

\subsection{Practical perspective}

Today's science and education system require to solve problems flexibly, quickly, and accurately, according to given rules of procedures. The ones who are not able to do so tend to have problems during their studies as well as in many ways within their practical life. This implies that it is useful to develop logical thinking. Methods for developing logical thinking include logic puzzles and logic tasks.

\section{LOGIC TASK}

Logic task is a task the solution of which can be obtained using rational (logical) reasoning applying elementary language skills, mathematics skills and knowledge. Logical reasoning means finding a suitable solution for an algorithm or applying a given algorithm to join or combine given elements.
This reasoning also means searching for the best possible options.

Logic in the so called logical reasoning means a particular process of thinking, ability to think or infer correctly, which means to draw conclusions from given knowledge or ideas. However, not every method (procedure) of reasoning necessarily needs to be logically correct: one can get from true assumptions to false conclusions. Logical reasoning is considered such reasoning which leads from true assumptions to true conclusions. In logic tasks a true conclusion is considered such solution which arises from a task assignment, respects all conditions and does not contradict any of the elements of such assignment. [1]

There is still one point to be added and it is that solution of true logic tasks can be deduced by sequence of successive steps of thoughts where one step is based on a second one. The solution can be reached via an algorithm which is either given in advance or needs to be compiled by the solver. These tasks concern, in particular, searching for and analyzing arrangement of elements [5], searching for relations (connections) among particular elements, searching for a system which includes elements of assignment.

Nevertheless, the broad category of logic tasks also includes tasks the solutions of which cannot be deduced using the above mentioned method. It includes various searching tasks, tasks based on attention, combined logical-and-knowledge tasks, etc. 


\section{LOGIC TASK OF THE ZEBRA TYPE}

Logic tasks of ZEBRA type are well-known particularly from the field of recreational mathematics. They are generally classified as difficult tasks. An obvious reason of ,difficulty "is a difficult communicability of individual steps of the logic procedure and a considerable degree of abstraction. However, solving this task type can be approached from the perspective of different strategies. By applying basics of structural and graphical methods in order to achieve solution, tasks become accessible not only for gifted students. [4] Individual steps are easier to be communicated and can be discussed. However there still remains some space for own personal presentations of students. This article deals with solutions for tasks of the ZEBRA type in more detail. Besides the intuitive problem-solving approach the attention is also paid to both the structural approach (solving tasks using a system of tables with logical relationships) and graphical approach (solving tasks using a a node graph).

\section{ASSOCIATIVE NETWORK}

Associative networks which are based on a graph representation of knowledge can be considered a tool for solving logic tasks. Associative networks, also well-known as semantic networks, are suitable as a tool for representing relationships (connections) among individual elements in the assignment.

The first mention of associative networks can be found in 1968 when they were designed as a model for human associative memory and have still been used to solve various tasks and problems; they have also been transferred to computer science. [4]

Logics [2] and semantic networks have a different formalism to represent knowledge. Several authors demonstrate that simple semantic networks may be expanded in the way that they, for example, are enhanced by an expressive power of the predicate logic. It means that the knowledge representation is based, equally as predicate logic, on atoms representing basic network statement by means of appropriately selected predicates. These statements are of vector nature $(<$ subject $><$ predicate/bearing a property $><$ object $>$ ). See Figure 1.

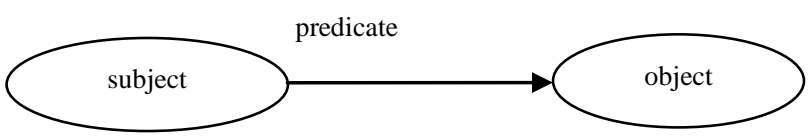

Figure 1. Vector of statement

Semantic network is an enhanced oriented graph consisting of nodes and edges. Each node represents an object (individuum) and each edge represents a relationship between two objects. Relationships between statements are of our interest because they provide basic structure for organized knowledge.

In associative networks the relationships can be well expressed by a set of inclusion and affiliation in a set; both the unique and general concepts can be represented here. Relationships of a set of inclusion and affiliation to a class enable to represent a taxonomic (hierarchical) arrangement of objects effectively. Thus deriving by specialization or by generalization can be carried out straightforwardly. As for specialization the information in taxonomy is transformed from general types to the specialized ones; as for generalization it is the contrary. Within one semantic network knowledge can be associated from many different perspectives. [3]

Semantic (associative) network is an enhanced oriented graph consisting of nodes, enhanced by terms, and of edges, enhanced by binary predicate symbols where the edges join some pairs of nodes.

Language of associative networks disposes of the following types of symbols:

\section{1) Nodes}

a) graphic symbols determining nodes of network

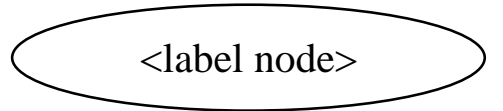

b) terms in signalling of nodes character strings

i) to determine variables (beginning with an uppercase letter): $\mathrm{X}, \mathrm{Y}, .$.

ii) to determine constants (beginning with a lowercase letter or a number): house, cat, $12, \ldots$

iii) for functional: $\sin (\mathrm{X}), \operatorname{mother}(\mathrm{X}), \ldots$

c) symbol for existential terms (beginning with the@symbol): @someone, @known(X),...

\section{2) Edges}

a) graphic symbols determining network edges

$$
\stackrel{<\text { label edge }>}{\longrightarrow}
$$

b) binary predicate symbols in signalling of edges: isa $(X, Y)$, live $(X, Y)$,

(attributes in parentheses are not indicated in the graph).

Atom of an associative network is formed by a vector consisting of two nodes, the signalling of which are the terms, and one connecting edge, the signalling of which is a predicate symbol. The associative network is formed by a set (not necessarily) of mutually interconnected atomic vectors.

\section{EXAMPLES OF LOGIC TASKS}

\section{Task 1}

Each of four sisters plays a different musical instrument and speaks different language. Mirka 
plays the cello. The one who speaks French plays the violin. Verra does not play the piano. Libuše does not speak German. Mirka speaks English. Jiřina does not play the violin. Vera does not speak French. Libuše does not play the flute. The pianist does not speak Italian. Which musical instrument does Věra play and which language does she speak?

Solution: Resulting solution procedure of this logic task is as follows:

1. Transcript of individual sentences of the logic task into the form of a graphical representation (rules) of associative networks - Figure 2. One sentence corresponds to one associative network. Negative sentences can be expressed using a negation sign.

2. Similar rules can be easily united to one associative network - Figure 3.

3. Rules which may not be united to one associative network should be left for next step - Figure 4.

4. The last step is logical reasoning by means of which one can unify the already united rules (Figure 3.) and last rules into four basic associative networks. Number of final associative networks corresponds to the number of sisters in accordance to the assignment - Figure 5 .

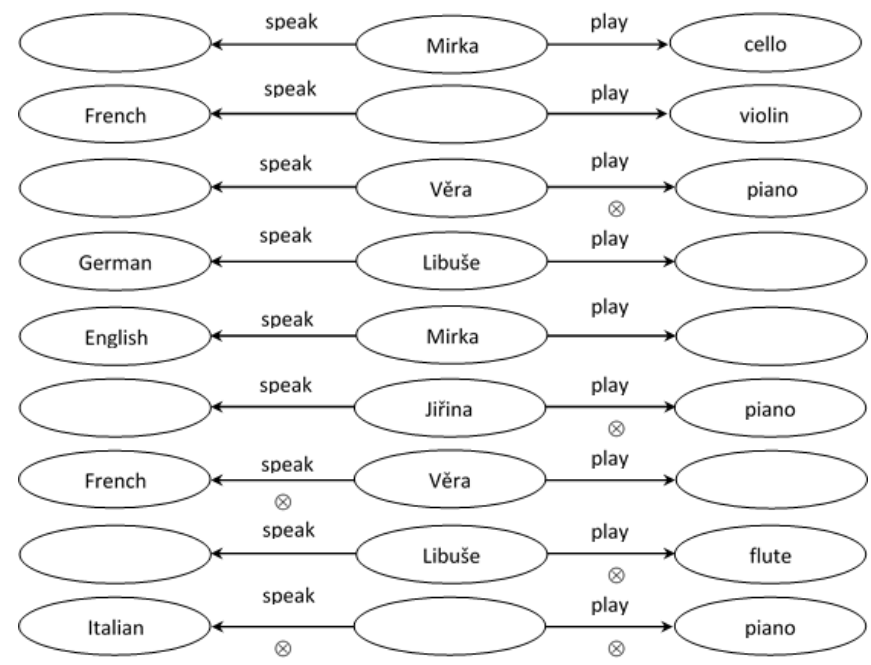

Figure 2. Expression of rules.

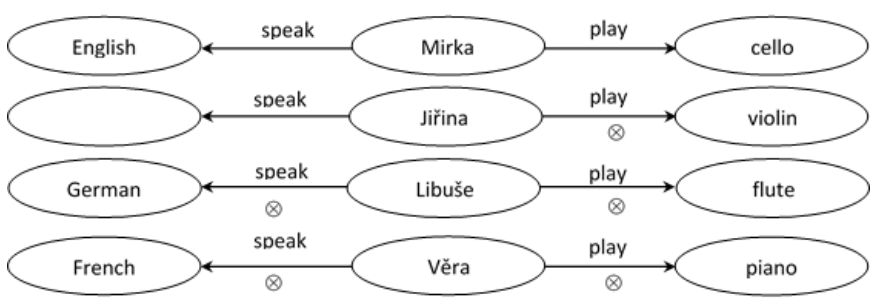

Figure 3. Unification of rules of semantic networks

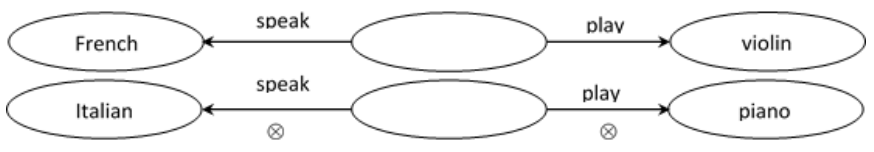

Figure 4. Remaining rules.

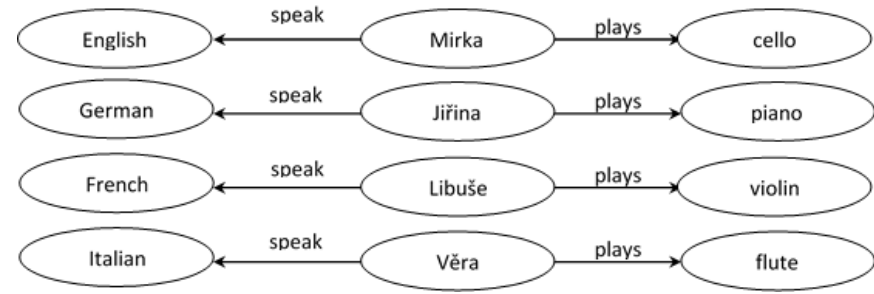

Figure 5. Evaluation - result.

Task 2 - logic task of the Einstein type

There are 5 animals lined up in a row according to their speed. Each animal belongs to a particular classification. These 5 animals eat different food, live in a different part of the world and belong to different orders according to their classification. None of these animals eats the same food, lives in the same place or belongs to the same orders.

Find out which animal eats little fishes, if you know:

1. Dragonfly is an insect.

2. Iguana belongs to the order of Squamata.

3. Cheetah lives in Africa.

4. Fish is faster than reptile.

5. Fish lives in the Atlantic Ocean

6. The animal that hunts flying insects belongs to the order of winged insects.

7. Bird hunts small birds.

8. The animal that is the third fastest lives in Europe.

9. Falcon is the fastest animal.

10. The animal that eats the ungulates is slower than the animal that belongs to the birds of prey.

11. The animal that belongs to the beasts of prey is slower than the animal that hunts small birds.

12. The animal that eats leaves of a variety of leafy greens lives in South America.

13. Swordfish belongs to the order of Perciformes

14. The animal that eats small ungulates is slower than the animal that lives in Iceland.

15. Falcon is faster than a mammal.

Who eats smaller fish?

During the last decade, we changing teaching methods at university [3] and changing approaches to in course. Tasks were tested in the course Knowledge Representation, where students were divided into two groups. Students solved simple and complicated logical task. The first group A used in solving the associative network and the second group B solved by any other method (most used table). From the observation, we found that $41 \%$ of students succeeded in solving simple problems (puzzles) and group B was faster than group A. In the case of more complex puzzles succeeded $47 \%$ of the students where group A was much faster than group B. In solving complex logic puzzles the success rate was greater than simple tasks and for the reason that students understand the principle solution. 
The study of our group, we can observe the following conclusions:

- Simple logical tasks should be solved with the table.

- For more complex logical problems is preferable to use an associative network.

\section{CONCLUSION}

Semantic networks can be easily expanded and transformed into a set of formulas of first-order logic and vice versa. However, the networks have two significant advantages, which make them the representatives in some applications (for instance understanding of natural languages). These two advantages include: very simple expression of the model, very readable representation which enables its easy visualization of derivation steps [6].

Use and application of semantic networks is wide, from computer science via mathematics up to representation of a natural language. The first task graphically demonstrates the use of a semantic network as a tool to solve an easy logic puzzle and the second task belongs to the Einstein types of tasks. Einstein is thought to create this original puzzle in the 19th century. He claimed that $98 \%$ of people all over the world is unable to solve it although there is no trick in the task, just logic. Even you can try and find out whether you belong to those $2 \%$ of the most intelligent people all over the world and what time you would need to handle the task! About 60 minutes is considered standard solution time but using the semantic network you can manage to complete the puzzle task even in 10 minutes.

\section{REFERENCES}

[1] EMMERLINGOVÁ, S. Můžeme se naučit logicky myslet? [on-line 25. 3. 2011] available at: http://www.energycentrum.cz/clanek/115_muzeme-senaucit-logicky-myslet

[2] HABIBALlA, H. Logika. Matematika - fyzika informatika. 2007, vol. 15, part 5, pp. 559-564. ISSN 1210-1761.

[3] KONEČNÁ, P. Training mathematics teacher profession ten years ago and now. Mathematica IV. Ružomberok: VERBUM, 2012. s. 83-90. ISBN 97880-8084-954-2.

[4] LUKASOVÁ, A., TELNAROVÁ, Z., HABIBALLA, H., VAJGL, M. Formální reprezentace znalostí. První. vyd. Ostrava: Universum, 2010. 345 p. dvanáctý svazek edice Universum. ISBN 978-80-7368-900-1.

[5] VOLNÁ, E. Umělá inteligence ve výuce informatiky. Conference proceedings ICTE 2001, Rožnov pod Radhoštěm, 2001

[6] ŽÁČEK, M. Použití sémantických sítí: Kategorie Věda má budoucnost. 2010. pp. 242-245. ISBN 978-80-7368719-9 